\title{
Dielectric and Optical Characterization of Boron Doped Ammonium Dihydrogen Phosphate
}

\author{
Delci Zion $^{1}$, Shyamala Devarajan ${ }^{1}$, Thayumanavan Arunachalam ${ }^{2}$ \\ ${ }^{1}$ Department of Physics, D.G.Vaishnav College, Chennai, India; ${ }^{2}$ Department of Physics, A.V.V.M. Sri Pushpam College, Thanjavur, \\ India. \\ Email: delcidgve@gmail.com
}

Received November $28^{\text {th }}, 2012$; revised December $31^{\text {st }}, 2012$; accepted January $10^{\text {th }}, 2013$

\begin{abstract}
Single crystals of pure and boron doped ammonium dihydrogen phosphate were grown from aqueous solution by slow solvent evaporation process. ICP studies were done to confirm the presence of the dopant boron in the parent crystal. The values of the lattice parameters were determined by single crystal X-ray diffraction. The pure and doped ADP crystals were found to have tetragonal structure. Complete optical characterizations of the crystals were done using the FTIR, UV-Vis and NLO studies. The presences of the various functional groups in the crystals were identified by FTIR spectrum. The band gap energies of the pure and doped crystals have been calculated at their cut off frequencies using the UV-Vis spectrum. The second harmonic generation efficiency of the crystals was determined. The electric properties of the grown crystal have been analyzed by studying the variation of dielectric constant and dielectric loss with frequency.
\end{abstract}

Keywords: Solution Growth; ADP; Boric Acid; Optical Transparency; NLO; Dielectric Constant

\section{Introduction}

Growth and studies of ammonium dihydrogen phosphate (ADP) crystal is a favourite topic to researchers because of its unique properties and wide applications. Single crystals of ADP are used for frequency doubling and frequency tripling of laser systems, optical switches in inertial confinement fusion and acoustic-optical devices $[1,2]$. ADP has been the subject of a wide variety of investigations over the past decades. Reasonable studies have been done on the growth and properties of pure ADP [3-5]. ADP belongs to scalenohedral class of tetragonal crystal systems. ADP has unit cell parameters of a $=\mathrm{b}=7.510 \AA$ and $\mathrm{c}=7.564 \AA[6,7]$. It is known that, very little amount of additives can strongly suppress the metal ion impurities and promote the crystal quality. Oxalic acid and amino acids as additives in ADP crystals give appreciable change in optical, thermal, dielectric and mechanical behaviours $[8,9]$. In a crystal metastable zone width is an essential parameter for the growth of good crystals from solution. Organic additives urea and thiourea increase the metastable zone width. In ADP crystal, using urea as additive, meta stable zone width increased by $3.7^{\circ} \mathrm{C}$, saturated at $30^{\circ} \mathrm{C}[10]$. The effect of additives depends on the additive concentration, super saturation, temperature and $\mathrm{PH}$. The growth promoting effect is observed in the presence of organic additives. In recent years, efforts have been taken to improve the quality, growth rate and properties of ADP, by employing new growth techniques, and also by the addition of organic, inorganic and semiorganic impurities [11-14]. In the light of the research work being done on ADP crystals, to improve the properties, the present work focuses on boron as a dopant in ADP and this is expected to enhance the nonlinearity of the crystal. We have studied and reported the optical and dielectric behaviour of boron doped ADP and pure ADP crystals.

\section{Materials and Method}

\section{Experimental Procedure}

All starting materials were of AR grade and the growth process was carried out in aqueous solution. The starting materials namely ADP and boric acid $\left(\mathrm{H}_{3} \mathrm{BO}_{3}\right)$ were taken in the ratio 1:0.1. The calculated amount of salts was dissolved in double dissolved water. This solution was then stirred well for more than six hours using a magnetic stirrer and filtered using Whatman filter paper. The solution was then poured into a Petri dish and allowed to evaporate at room temperature. Optically good quality single crystals of dimension $12.6 \times 5.2 \times 2.8 \mathrm{~mm}^{3}$ were harvested in a period of $20-25$ days. The photograph of the as grown crystal of pure ADP and boron 
doped ADP are shown in Figures 1(a) and 1(b).

\section{Structural Confirmation}

\subsection{ICP Studies}

In ICP technique, the wavelength at which emission occurs identifies the element and quantifies its concentration. So in boron doped ADP, ICP studies were conducted to identify the boron content in the grown crystal. The concentration of the boron was found to be $210 \mathrm{ppm}$. So the presence of dopant was confirmed by the ICP technique.

\subsection{Single Crystal X-Ray Diffraction Studies}

The single crystal X-ray diffraction analysis on the grown crystals was done using Bruker Kappa APEX II single crystal X-ray diffractometer at IIT, Chennai, to determine the unit cell dimensions. The lattice parameters determined are presented in Table1. It was seen that there is only a slight variation in the values of the lattice parameters. Both of them belong to tetragonal I4-2d space group. This implies that the structure is not cha-

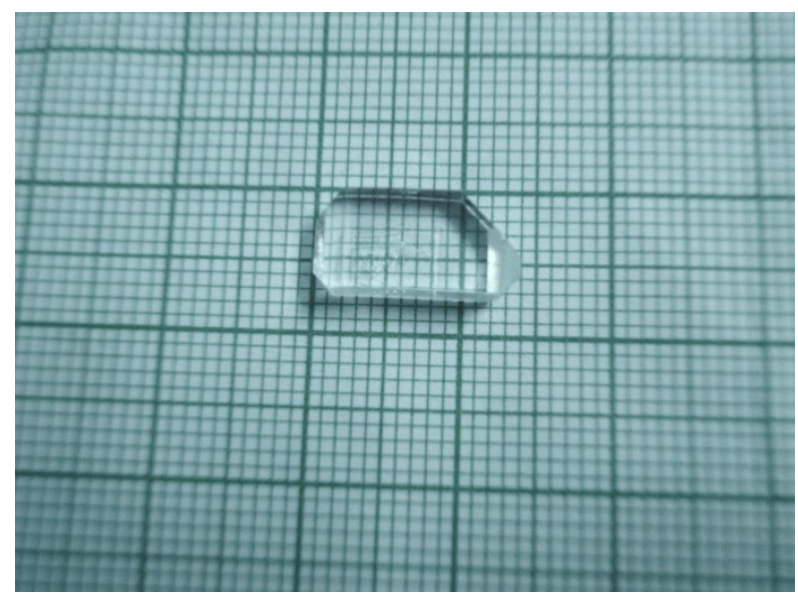

(a)

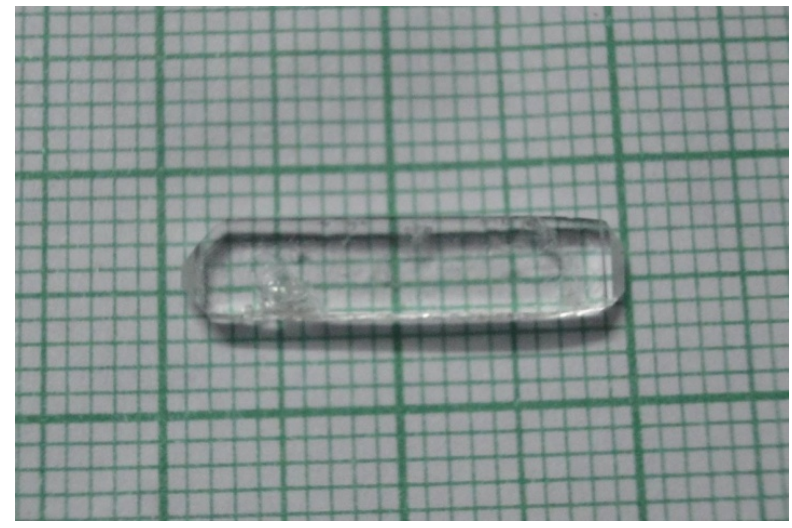

(b)

Figure 1. (a) Photograph of the as grown pure ADP crystals; (b) Photograph of the as grown boron doped ADP crystals. nged due to the presence of the dopant but the influence of the dopant with respect to the properties was further investigated.

\section{Optical Characterization}

\subsection{FTIR}

The Fourier transform infrared spectrum of pure ADP and boron doped ammonium dihydrogen phosphate crystals were recorded using Perkin Elmer model RXI Spectrometer in the range $400-4000 \mathrm{~cm}^{-1}$. The recorded spectrum is given in Figures 2 and 3. The strong band centred at about $3933 \mathrm{~cm}^{-1}$ is generally $\mathrm{O}-\mathrm{H}$ due to $\mathrm{OH}$ stretching and water bending. The strong and broad band at $3420 \mathrm{~cm}^{-1}$ is due to $\mathrm{KBr}$ null absorption, which appears in the spectrum of any compound [15]. The band at $2353 \mathrm{~cm}^{-1}$ can be assigned to a second overtone of P-O deformation vibration appearing near $910 \mathrm{~cm}^{-1}$. The PO stretching vibration leads to a distinct band at $1288 \mathrm{~cm}^{-1}$. At room temperature $\mathrm{PO}_{4}^{-3}$ is a symmetric complex anion. The $\mathrm{P}=\mathrm{O}$ deformation vibrations are found between 840 and $1120 \mathrm{~cm}^{-1}$ [16]. At 552 and $459 \mathrm{~cm}^{-1} \mathrm{P}=\mathrm{O}-\mathrm{H}$ wagging and rocking vibrational bandsare found. The spectrum of boron doped ADP is almost the same as pure ADP except that a few shifting of peaks is noticed. The $\mathrm{B}=\mathrm{O}$ stretching which usually occurs at $1651 \mathrm{~cm}^{-1}$ is found to be shifted to $1715 \mathrm{~cm}^{-1}$. Also the $\mathrm{P}=\mathrm{O}$ deformation at $459 \mathrm{~cm}^{-1}$ has disappeared in the FTIR spectrum of boron doped ADP. These effects can be due to the presence of boron in the crystal influencing the $\mathrm{P}=\mathrm{O}$ functional group. A detailed assignment of the frequencies observed in the FTIR spectrum is given Table 2.

\subsection{UV-Vis Spectral Studies}

Optical absorption data collected for the pure and doped ADP polished sample is shown in Figure 4. The measurements were done using Perkin Elmer Model-Lambda 35 spectrometer between $200-1200 \mathrm{~nm}$. The spectrum indicates that the pure and doped ADP crystals have minimum absorption in the entire region between 200 $1200 \mathrm{~nm}$. It is seen that the doped ADP crystal has better lower cut off wavelength than that of pure ADP crystal. It is interesting to note that the boron doped ADP crystal has reduced absorption when compared to pure ADP. It is already well established that if the UV-Vis spectrum of

Table 1. Unit cell parameters of pure ADP and boron doped ADP crystals.

\begin{tabular}{cccccc}
\hline Sample & $\left.\begin{array}{c}\text { Lattice parameter } \\
\mathrm{A}=\mathrm{b}, \mathrm{c}(\AA)\end{array}\right)$ & $\begin{array}{c}\text { Cell volume } \\
\left(\AA^{3}\right)\end{array}$ & $\begin{array}{c}\alpha=\beta=\gamma \\
\text { Structure }\end{array}$ \\
\hline Pure ADP & 7.491 & 7.546 & 423 & $90^{\circ}$ & Tetragonal \\
Boron doped ADP & 7.512 & 7.564 & 426 & $90^{\circ}$ & Tetragonal \\
\hline
\end{tabular}


Table 2. Observed FTIR frequencies $\left(\mathrm{cm}^{-1}\right)$ of pure ADP and boron doped ADP crystals.

\begin{tabular}{|c|c|c|}
\hline \multicolumn{2}{|c|}{$\begin{array}{l}\text { Observed FTIR Frequencies } \\
\qquad\left(\mathrm{cm}^{-1}\right)\end{array}$} & \multirow[t]{2}{*}{ Assignments } \\
\hline Pure ADP & Boron Doped ADP & \\
\hline $3933 \mathrm{M}$ & $3935 \mathrm{VS}$ & $\mathrm{O}-\mathrm{H}$ Stretching and Water Bending \\
\hline $3125 \mathrm{VW}$ & $3139 \mathrm{VW}$ & B-OH Stretching \\
\hline $2890 \mathrm{M}$ & - & $\mathrm{N}-\mathrm{H}$ Stretching of Ammonia \\
\hline $2353 \mathrm{~W}$ & $2428 \mathrm{~W}$ & Combination Band of Vibrations \\
\hline $1651 \mathrm{VW}$ & $1715 \mathrm{VW}$ & Asymmetric B-O Stretching \\
\hline $1409 \mathrm{VW}$ & $1411 \mathrm{VW}$ & Bending Vibration of Ammonia \\
\hline $1288 \mathrm{VW}$ & $1289 \mathrm{VW}$ & P-O Stretching Vibration \\
\hline $1098 \mathrm{VW}$ & $1099 \mathrm{VW}$ & P-O-H Vibration \\
\hline $910 \mathrm{VW}$ & $910 \mathrm{VW}$ & P-O-H Vibrations \\
\hline $552 \mathrm{~W}$ & $555 \mathrm{~W}$ & $\mathrm{PO}_{4}$ Vibrations \\
\hline $459 \mathrm{M}$ & - & $\mathrm{PO}_{4}$ Vibration \\
\hline
\end{tabular}

VS: very strong; S: strong; M: medium; W: weak; VW: very weak.

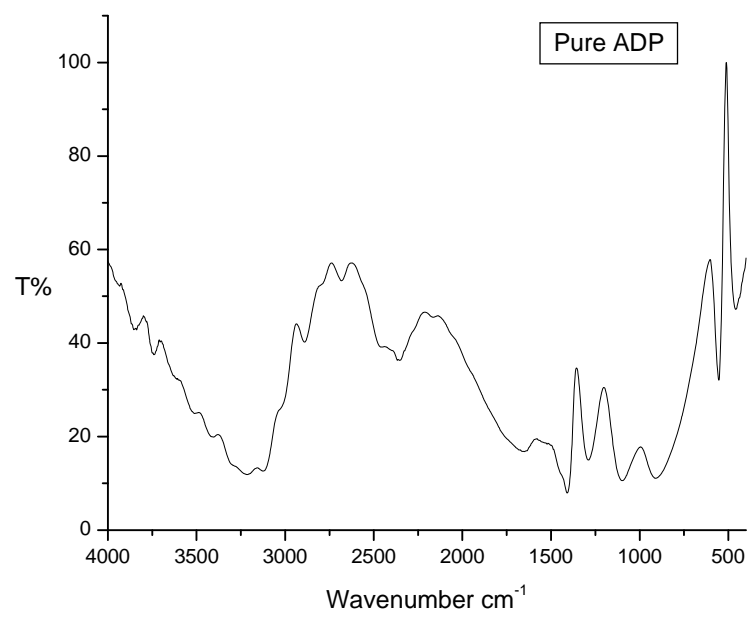

Figure 2. FTIR spectrum of pure ADP crystal.

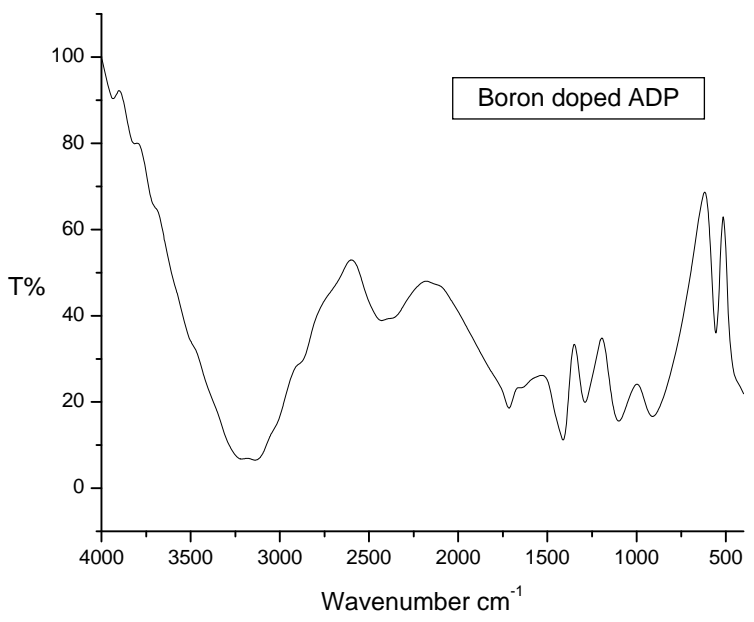

Figure 3. FTIR spectrum of boron doped ADP crystal.

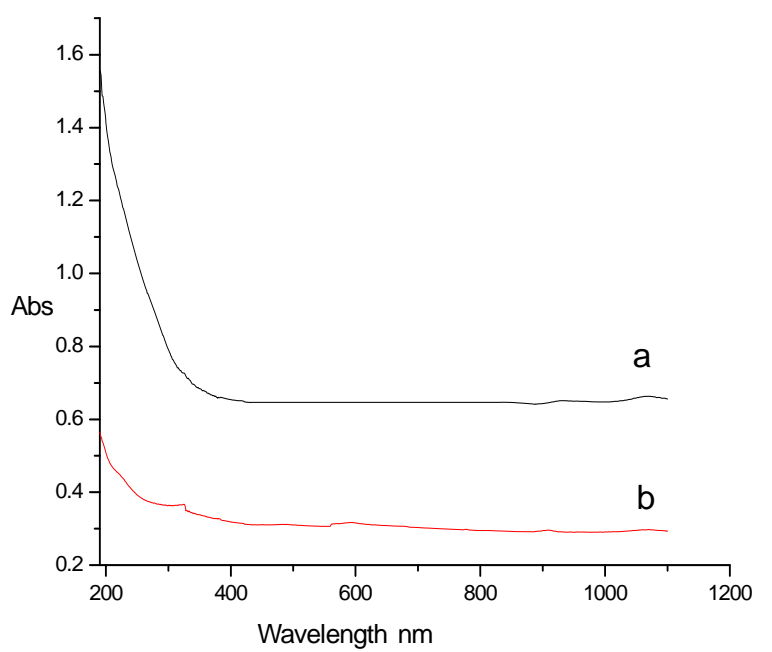

Figure 4. UV-Vis spectrum of (a) pure ADP (b) boron doped ADP crystal.

a crystal shows minimum absorption and lower cut off wavelength then the probability that the crystal is NLO active is more. It is observed that in boron doped ADP the above stated condition is satisfied hence it can be concluded that the crystal is NLO active. Absorption in the near ultraviolet region arises from electronic transitions associated within the sample. Using the formula Eg $=\mathrm{hc} / \lambda$, the band gap energies were found where $\mathrm{h}$ is the Planck's constant and c is the velocity of light. It was seen that the band gap energy is $4.1 \mathrm{eV}$ for pure ADP and $4.7 \mathrm{eV}$ for doped ADP. Therefore the improved band gap energy of $4.7 \mathrm{eV}$ and better crystal transparency in doped ADP can be attributed to the presence of boron.

\subsection{SHG Studies}

To conform the NLO nature, the grown crystals of pure and doped ADP were subjected to Kurtz-Perry Second Harmonic Generation (SHG) test using the Nd: YAG Q switched laser beam. The second harmonic signal of 3.6 $\mathrm{mJ}$ and $4.7 \mathrm{~mJ}$, respectively were obtained for pure and boron doped ADP. Thus, the SHG efficiency of boron doped crystal is nearly 1.31 times greater than pure ADP.

\section{Dielectric Studies}

The dielectric analysis is an important characteristic that can be used to fetch knowledge based on the electrical properties of a material medium as a function of temperature and frequency. Based on this analysis, the capability of storing electric charges by the material and capability of transferring the electric charge can be assessed. Dielectric properties are correlated with electro optic property of the crystals: particularly when they are non conducting materials [17]. The dielectric constant and dielectric loss of pure and doped ADP crystals were determined using Multi-frequency LCR meter (LCR-800 
SERIES). Samples were cut to a proper thickness and polished. Each sample was electroded on both sides with high purity silver paste so that it behaved like a parallel plate capacitor. The dielectric constant is calculated using the formula

$$
\varepsilon_{\mathrm{r}}=\mathrm{Ct} / \varepsilon_{\mathrm{o}} \mathrm{A}
$$

where $\mathrm{C}$ is capacitance $(\mathrm{F}), \mathrm{t}$ the thickness $(\mathrm{m}), \mathrm{A}$ the area $\left(\mathrm{m}^{2}\right)$, and $\varepsilon_{0}$ the absolute permittivity in the free space having a value of $8.854 \times 10^{-12} \mathrm{~F} \cdot \mathrm{m}^{-1}$. Repeated trials were performed to ascertain the correctness of the observed results.

Figures 5-8 show the variation of dielectric constant and dielectric loss with respect to frequency for temperatures $\left(40^{\circ} \mathrm{C}, 80^{\circ} \mathrm{C}, 120^{\circ} \mathrm{C}\right.$ and $\left.160^{\circ} \mathrm{C}\right)$ for both pure and boron doped ADP crystals. From Figures 5 and 7, it is seen that the dielectric constant increases with the increase in temperature for both pure and boron doped

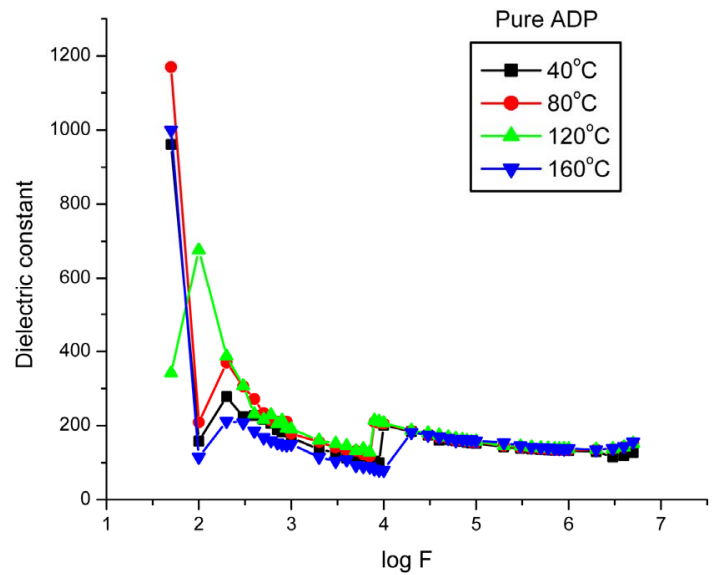

Figure 5. Variation of dielectric constant with frequency at different temperature.

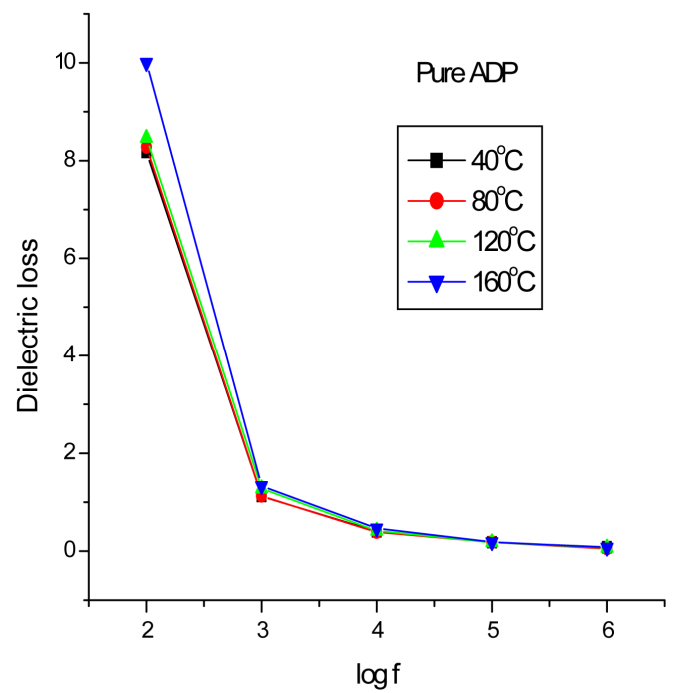

Figure 6. Variation of dielectric loss with frequency at different temperature.
ADP crystals. Compared to the pure ADP, the dielectric constant $\left(\varepsilon_{\mathrm{r}}\right)$ of doped ADP is lesser in value. This is found to be similar to the data as reported in pure and urea-doped KDP single crystals [18]. The magnitude of dielectric constant depends on the degree of polarization in the crystals. It was seen that the dielectric constant has high value in the lower frequency region and then it decreases with the increasing frequency. In Figures $\mathbf{6}$ and $\mathbf{8}$, that dielectric loss is high at low frequency and decreases with higher frequencies.

A low dielectric loss at high frequency implies that the optical quality of the crystal is higher because of lesser defects, which is a desirable property for NLO applica-

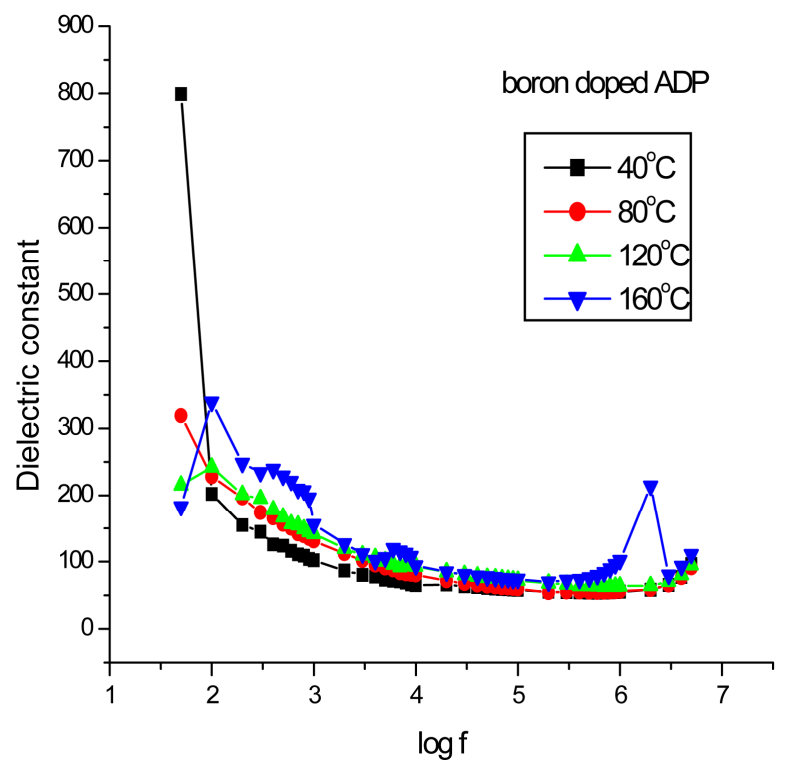

Figure 7. Variation of dielectric constant with frequency at different temperature.

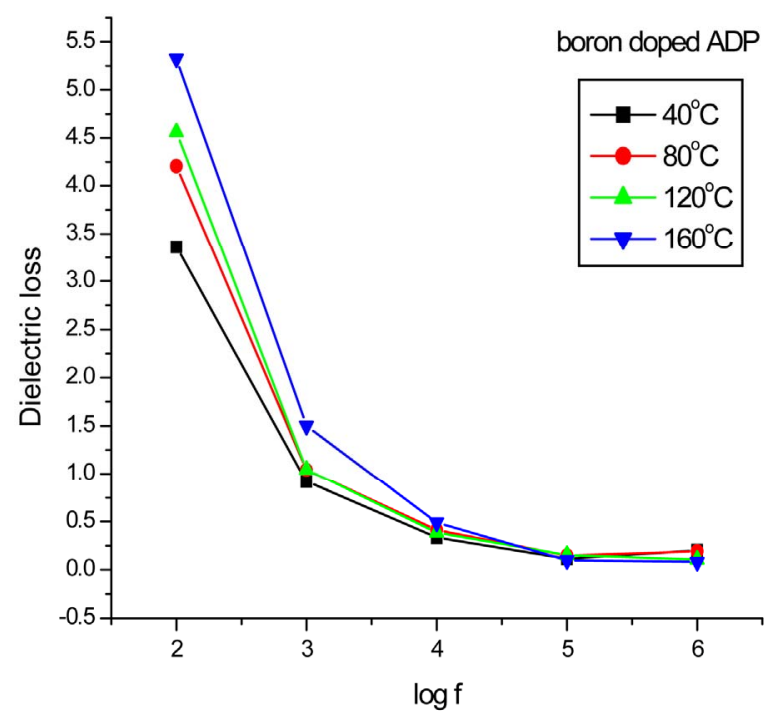

Figure 8. Variation of dielectric loss with frequency at different temperature. 
tions [19]. The variation of dielectric constant with temperatures at frequencies $100 \mathrm{~Hz}, 1 \mathrm{KHz}, 10 \mathrm{KHz}, 100$ $\mathrm{KHz}$ and $1 \mathrm{MHz}$ was determined. The results are shown in Figures 9-12. It was found that the values of dielectric constant and dielectric loss increase with an increase in temperature and decrease with the increasing frequency. At low frequencies the dipoles can easily switch alignment with the changing field [20]. As the frequency increases the dipoles can rotate less and maintain phase with the field; thus they reduce their contribution to the polarization field, and hence the observed reduction in dielectric constant and dielectric loss. According to Miller rule, the lower value of dielectric constant at higher frequencies is a suitable parameter for the enhancement of SHG coefficient $[21,22]$. The low dielectric loss with

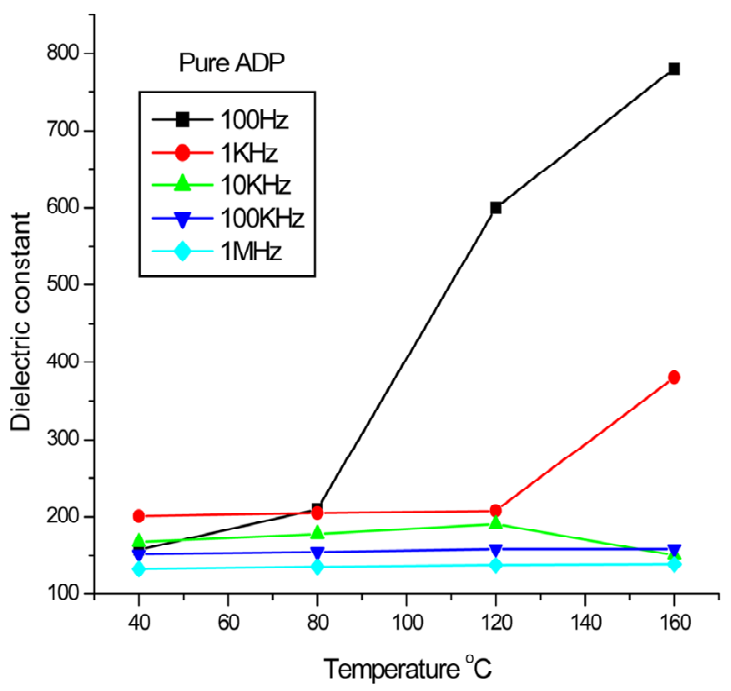

Figure 9. Variation of dielectric constant with temperature at different frequencies.

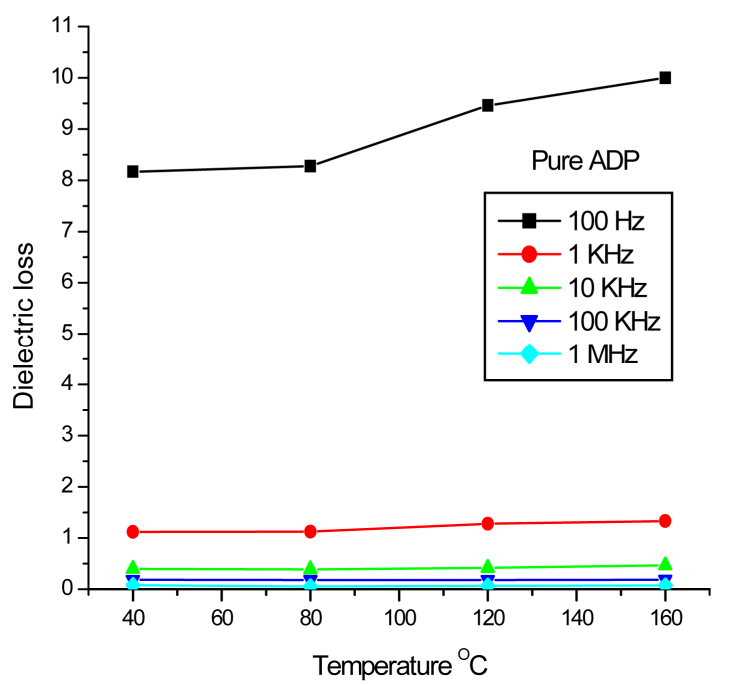

Figure 10. Variation of dielectric loss with temperature at different frequencies.

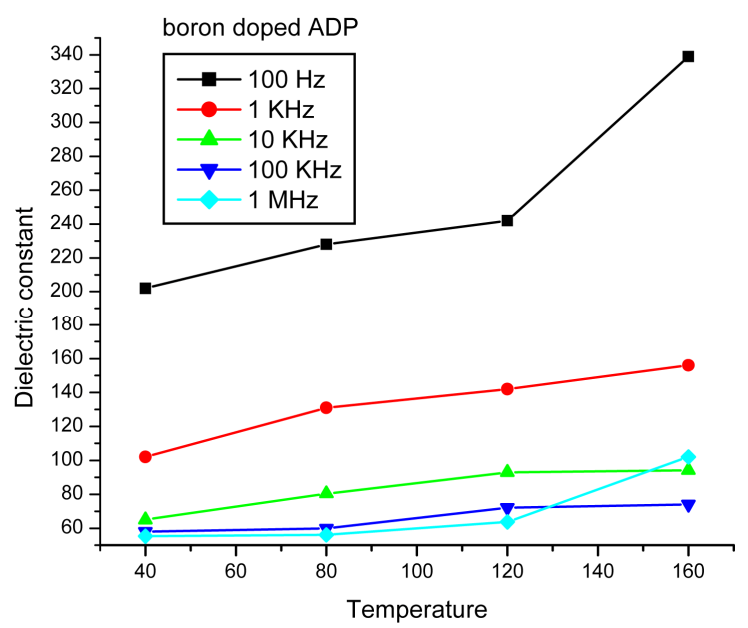

Figure 11. Variation of dielectric constant with temperature with temperature at different frequencies.

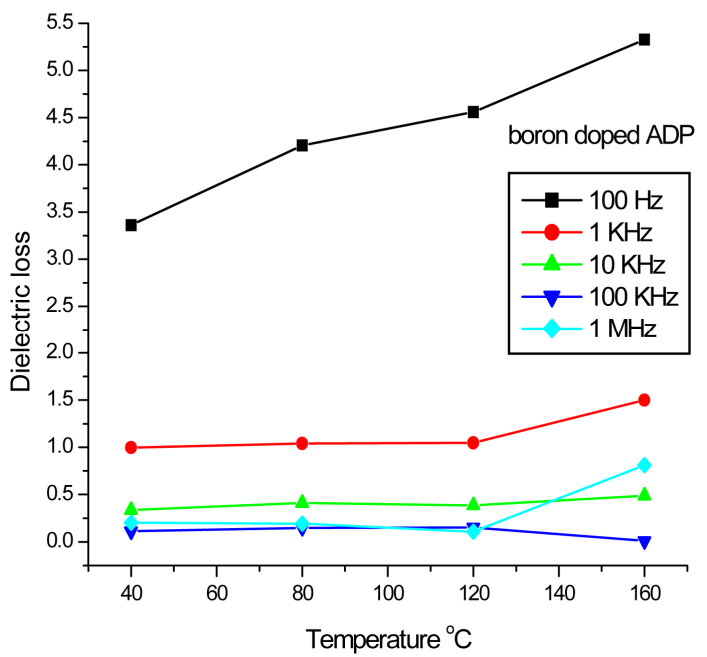

Figure 12. Variation of dielectric loss with temperature at different frequencies.

high frequency for a given sample suggests that the sample possesses enhanced optical quality with lesser defects and this parameter is of vital importance for nonlinear optical materials [23,24]. In the case of boron doped ADP there is an appreciable decrease in dielectric constant value compared to pure ADP suggesting the possibility of realizing ADP crystals with low $\varepsilon_{\mathrm{r}}$ value.

\section{Conclusion}

Pure and boron doped ADP single crystals were grown by slow evaporation technique at room temperature. Colourless and transparent crystals were obtained. The presence of boron in ADP was confirmed by ICP. Both the crystals are found to belong to the same tetragonal I4-2d space group. The values of lattice parameter of both pure and doped samples show no appreciable difference. In the Fourier transform infrared spectrum the 
dopant boron was found to effectively influence the P-O stretching and deformation. From the UV-Vis spectrum the band energy of the doped ADP was calculated to be $4.7 \mathrm{eV}$ suggesting a positive NLO activity. The crystal has a wide transmission window ranging from 300 to $1100 \mathrm{~nm}$. The SHG efficiency is 1.3 times greater than pure ADP and this suggests that boron doped ADP is a promising candidate for NLO applications. The lower value of dielectric constant and dielectric loss on doping with boron is observed. From the above characterization studies it is concluded that the addition of boron in pure ADP has enhanced the transparency and NLO efficiency of ADP crystals. So it is suggested that the crystal is a potential candidate for the fabrication of NLO devices.

\section{REFERENCES}

[1] D. Xu and D. Xue, "Chemical Bond Simulation of KADP Single-Crystal Growth," Journal of Crystal Growth, Vol. 310, No. 7-9, 2008, pp. 1385-1390. doi:10.1016/j.jcrysgro.2007.12.008

[2] R. J. Davey and J. W. Mullin, "Growth of the $\{100\}$ Faces of Ammonium Dihydrogen Phosphate Crystals in the Presence of Ionic Species," Journal of Crystal Growth, Vol. 26, 1974, p. 45.

[3] K. Sethuraman, R. R. Babu, R. Gopalakrishnan and P. Ramasamy, "Unidirectional Growth of $\left(\begin{array}{lll}1 & 1 & 0\end{array}\right)$ Ammonium Dihydrogen Orthophosphate Single Crystal by Sankaranarayanan-Ramasamy Method," Journal of Crystal Growth, Vol. 294, No. 2, 2006, pp. 349-352. doi:10.1016/j.jcrysgro.2006.06.033

[4] S. Nagalingam, S. Vasudevan and P. Ramasamy, "Effect of Impurities on the Nucleation of ADP from Aqueous Solution," Crystal Research and Technology, Vol. 16, No. 6, 1981, p. 647-650.

[5] R. Ramesh and C. Mahadevan, "Nucleation Studies in Supersaturated Aqueous Solutions of $\left(\mathrm{NH}_{4}\right) \mathrm{H}_{2} \mathrm{PO}_{4}$ Doped with $\left(\mathrm{NH}_{4}\right)_{2} \mathrm{C}_{2} \mathrm{O}_{4} \cdot \mathrm{H}_{2} \mathrm{O}$," Bulletin of Materials Science, Vol. 21, No. 4, 1998, pp. 287-290.

doi:10.1007/BF02744954

[6] M. E. Lines and A. M. Glass, "Principles and Applications of Ferroelectrics and Related Materials," Clarendon Press, Oxford, 1977.

[7] N. P. Rajesh, K. Meera, K. Srinivasan, S. Ragavan and P. Ramasamy, "Effect of EDTA on the Metastable Zone width of ADP," Journal of Crystal Growth, Vol. 213, No. 3-4, 2003, pp. 389-394. doi:10.1016/S0022-0248(00)00374-2

[8] K. Srinivasan, P. Ramasamy, A. Cantoni and G. Bocelli, "Mixed Crystals of $\mathrm{NH}_{4} \mathrm{H}_{2} \mathrm{PO}_{4}-\mathrm{KH}_{2} \mathrm{PO}_{4}$ : Compositional Dependence of Morphology, Microhardness and Optical Transmittance," Materials Science and Engineering: B, Vol. 52, No. 2-3, 1998, pp. 129-133. doi:10.1016/S0921-5107(97)00286-9

[9] M. Yoshimatsu, "Some Observations of Imperfections in ADP Single Crystals by X-Ray Diffraction Micrography," Japanese Journal of Applied Physics, Vol. 5, 1966, pp. 29-35. doi:10.1143/JJAP.5.29

[10] R. Reintjes and E. C. Eckardt, "Evaporated Inhomogeneous Thin Films," Applied Optics, Vol. 5, No. 1, 1966, pp. 29-34. doi:10.1364/AO.5.000029

[11] P. Kumaresan, S. M. Babu and P. M. Anbasan, "Thermal, Dielectric Studies on Pure and Amino Acid (1-Glutamic Acid, 1-Histidine, 1-Valine) Doped KDP Single Crystals," Optical Materials, Vol. 30, No. 9, 2008, pp. 1361-1368. doi:10.1016/j.optmat.2007.07.002

[12] P. Rajesh and P. Ramasamy, "Growth of DL-Malic AcidDoped Ammonium Dihydrogen Phosphate Crystal and Its Characterization," Journal of Crystal Growth, Vol. 311, No. 13, 2009, pp. 3491-3497. doi:10.1016/i.jerysgro.2009.04.020

[13] J. Podder, "The Study of Impurities Effect on the Growth and Nucleation Kinetics of Potassium Dihydrogen Phosphate," Journal of Crystal Growth, Vol. 237-239, No. 1, 2002, pp. 70-75. doi:10.1016/S0022-0248(01)01854-1

[14] P. V. Dhanaraj, G. Bhagavanarayana and N. P. Rajesh, "Effect of Amino Acid Additives on Crystal Growth Parameters and Properties of Ammonium Dihydrogen Orthophosphate Crystals," Materials Chemistry and Physics, Vol. 112, No. 2, 2008, pp. 490-495.

[15] T. Ananthi, S. M. Delphine, M. M. Freeda, R. K. Priya and A. Wahabmusallam, "Growth and Characterization of Doped ADP Crystal," Recent Research in Science and Technology, Vol. 3, No. 1, 2011, pp. 32-40.

[16] Z. Delci, D. Shyamala, S. Karuna, A. Senthil and A. Thayumanavan, "Enhancement of Optical, Thermal and Hardness in KDP Crystals by Boron Doping," International Journal of ChemTech Research, Vol. 4, No. 2, 2012, pp. 816-826.

[17] S. Boomadevi, H. P. Mittal and R. Dhansekaran, "Synthesis, Crystal Growth and Characterization of 3-Methyl 4Nitropyridine 1-Oxide (POM) Single Crystals," Journal of Crystal Growth, Vol. 261, No. 1, 2004, pp. 55-62. doi:10.1016/j.jcrysgro.2003.09.005

[18] B. T. Hatton, K. Landskron, W. J. Hunks, et al., "Materials Chemistry for Low-K Materials," Materials Today, Vol. 9, No. 3, 2006, pp. 22-31. doi:10.1016/S1369-7021(06)71387-6

[19] S. Goma, C. M. Padma and C. K. Mahadevan, "Dielectric Parameters of KDP Single Crystals Added with Urea," Materials Letters, Vol. 60, No. 29-30, 2006, pp. 37013705. doi:10.1016/j.matlet.2006.03.092

[20] S. Suresh, A. Ramanand, D. Jayaraman and P. Mani, "Growth, Photoconductivity and Dielectric Properties of Triglycine Sulfate (TGS) Single Crystals," Optoelectronics and Advanced Materials, Vol. 4, No. 11, 2010, pp. 1763-1765.

[21] C. Balarew and R. Duhlew, "Application of the Hard and Soft Acids and Bases Concept to Explain to Ligand Coordination in Double Salt Structures," Journal of Solid State Chemistry, Vol. 55, No. 1, 1984, pp. 1-6. doi:10.1016/0022-4596(84)90240-8

[22] M. Meena and C. K. Mahadevan, "Growth and Electrical Characterization of L-Arginine Added KDP and ADP Single Crystals," Crystal Research and Technology, Vol. 43, No. 2, 2008, pp. 166-172. 


\section{doi:10.1002/crat.200711064}

[23] S. Aruna, G. Bhagavannarayana, M. Palanisamy, P. C. Thomas, B. Varghese and P. Sagayaraj, "Growth, Morphological, Mechanical and Dielectric Studies of Semi Organic NLO Single Crystal: 1-Argininium Perchlorate," Journal of Crystal Growth, Vol. 300, No. 2, 2007, pp. 403-408. doi:10.1016/j.jcrysgro.2006.11.296
[24] N. Pattanaboonmee, P. Ramasamy, R. Yimnirun and P. Manyum, "A Comparative Study on Pure, 1-Arginine and Glycine Doped Ammonium Dihydrogen Orthophosphate Single Crystals Grown by Slow Solvent Evaporation and Temperature Gradient Method," Journal of Crystal Growth, Vol. 314, No. 1, 2010, pp. 196-201. 